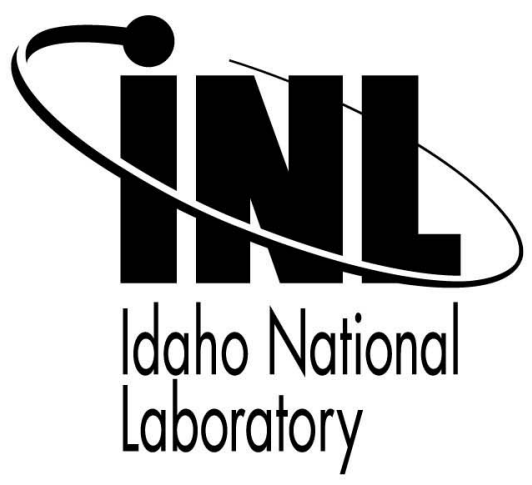

\section{ASME Pressure Vessels and Piping Division Conference}

\author{
Dana K. Morton \\ Spencer D. Snow \\ Tom E. Rahl \\ Robert K. Blandford
}

July 2007

This is a preprint of a paper intended for publication in a journal or proceedings. Since changes may be made before publication, this preprint should not be cited or reproduced without permission of the author. This document was prepared as an account of work sponsored by an agency of the United States Government. Neither the United States Government nor any agency thereof, or any of their employees, makes any warranty, expressed or implied, or assumes any legal liability or responsibility for any third party's use, or the results of such use, of any information, apparatus, product or process disclosed in this report, or represents that its use by such third party would not infringe privately owned rights. The views expressed in this paper are not necessarily those of the United States Government or the sponsoring agency. 
PVP2007-26182

\title{
IMPACT TESTING OF STAINLESS STEEL MATERIAL AT ROOM AND ELEVATED TEMPERATURES ${ }^{1}$
}

\author{
Dana K. Morton \\ Spencer D. Snow, Tom E. Rahl, Robert K. Blandford \\ Idaho National Laboratory \\ P.O. Box 1625 \\ Idaho Falls, Idaho $83415-3760$ \\ United States of America \\ (208) 526-1274, (208) 526-4311, Dana.Morton@inl.gov
}

\begin{abstract}
Stainless steels are used for the construction of numerous spent nuclear fuel or radioactive material containers that may be subjected to high strains and moderate strain rates during accidental drop events. Mechanical characteristics of these base materials and their welds under dynamic loads in the strain rate range of concern are not well documented. However, three previous papers $[1,2,3]$ reported on impact testing and analysis results performed at the Idaho National Laboratory using 304/304L and 316/316L stainless steel base material specimens that began the investigation of these characteristics.

The goal of the work presented herein is to add the results of additional tensile impact testing for dual-marked 304/304L and $316 / 316 \mathrm{~L}$ stainless steel material specimens (hereafter referred to as $304 \mathrm{~L}$ and $316 \mathrm{~L}$, respectively). Utilizing a dropweight impact test machine and 1/4-inch to $1 / 2$-inch thick dogbone shaped test specimens, additional impact tests achieved target strain rates of 5,10 , and 22 per second at room temperature, 300, and 600 degrees Fahrenheit. Elevated true stress-strain curves for these materials at each designated strain rate and temperature are presented herein.
\end{abstract}

\section{INTRODUCTION}

The Department of Energy's (DOE) National Spent Nuclear Fuel Program (NSNFP), working with the Office of Civilian Radioactive Waste Management (OCRWM), the Idaho National Laboratory (INL), and other DOE sites, has supported the development of canisters for loading and interim storage, transportation, and disposal of DOE spent nuclear fuel (SNF). These canisters must be capable of performing a variety of functions during all three of these designated uses. Handling and transport operations require that the canister design have a high degree of confidence against failure of the containment boundary if the canister is subjected to loads (e.g., accidental drop events) resulting in large plastic deformations and high strains, strains which would likely occur over a range of moderate strain rates ( 5 to 200 per second). The first phase of material impact testing at -20 , room, 300 , and $600^{\circ} \mathrm{F}$ temperatures is addressing strain rates below 40 per second and is still on going. Higher strain rates of interest ( 40 to 200 per second) at the same temperature conditions are to be investigated in the future. Both base and weld materials are to be investigated.

To assess the containment integrity of these SNF canisters under dynamic impact loading, the preferred approach is to use nonlinear plastic analytical methods with limited confirmatory testing. Improved software and methodologies for performing inelastic, large deformation analyses are now common and offer numerous advantages relative to full-scale component testing, including relatively low cost analytical simulations, ease of evaluating material and design options, elimination of costs associated with actual fabrication, testing, and post-test disposal, etc. In order to rely only on an analytical approach, accurate results from methodologies and software must be demonstrated which in turn mandate a precise definition of inelastic, dynamic material properties (e.g. true stress-strain

${ }^{1}$ Work supported by the U. S. Department of Energy, Office of Environmental Management (National Spent Nuclear Fuel Program at the Idaho National Laboratory) under DOE Idaho Operations Office Contract No. DE-AC07-05ID14517. 
curves reflecting strain rate effects). Other variables such as temperature, welded and aged material properties, and project specific conditions (if appropriate) must also be considered.

The INL developed a drop-weight impact testing machine (ITM) to begin the consideration of these variables and determine elevated strain rate stress-strain curves for stainless steel materials. A high-speed digital camera is used to record the deformation time history of the impact event. The slope of the initial strain versus time curve yields the strain rate, as indicated in Figure 1 below. Previous ASME PVP Conference papers [1, 2, and 3] described the ITM, the basic testing methodology, and associated results.

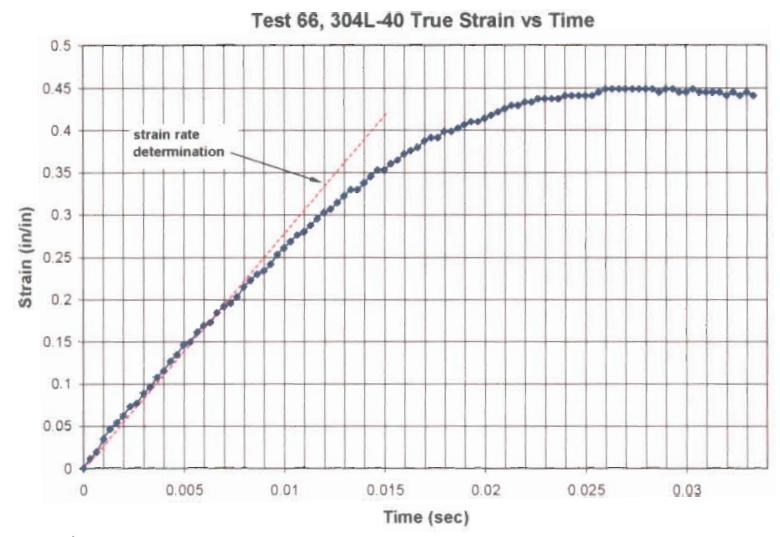

Figure 1. Strain Rate Determined Using High Speed Camera Data

A "total impact energy method" was developed using the concept that the area under a true stress-strain curve is equivalent to the amount of energy a volume of material can absorb up to a specific strain level achieved in the material. The total impact energy method develops an elevated strainrate true stress-strain curve by multiplying each stress point on the quasi-static curve by a constant (referred to as the "factor value'). The constant is the ratio of the impact energy imparted to the test specimen divided by the area under the quasi-static true stress-strain curve up to the strain achieved in the impact test specimen. Elevated true stress-strain curves (reflecting strain rate effects) produced using this method are considered valid up to the uniform strain limit (onset of necking) of the material. Future testing and analysis efforts may better define the curve between the uniform strain limit and failure.

Referenced papers 1 and 2 presented results for test specimens with a short gage length. Reference 1 showed a $316 \mathrm{~L}$ test specimen with a 1.5 -inch gage length and Reference 2 used $304 \mathrm{~L}$ test specimens with a 1.5 -inch gage length to achieve 50 per second strain rates. Additional data evaluation efforts regarding the uniform strain response of these test specimens (completed after the papers were presented) indicated that end effects become very significant with these shorter gage lengths, causing the strain distribution along the gage length to not be as uniform as that achieved with longer gage lengths. That in-depth data evaluation process indicated that a minimum gage length of 3 inches is necessary for a good uniform strain distribution along the gage length. Test specimens reported herein had gage lengths equal to or greater than 3 inches.

\section{IMPACT TESTING AT VARYING TEMPERATURES}

Room temperature testing was achieved at $70^{\circ} \mathrm{F}+15 /$ $-18^{\circ} \mathrm{F}$ in older facilities with limited temperature controls during the fall, winter, spring, and summer seasons. The elevated test specimen temperatures were achieved by heating the test specimens with four symmetrically placed heat guns. Temperature baseline testing was performed that established the number of electric heat guns to be used, their placement, the timing necessary to achieve stable target temperature conditions, the timing necessary to achieve acceptable temperatures at impact, and the timing necessary to make repetitive tests in one test day. The baseline temperature testing was completed using a test specimen with five thermocouples embedded to the centerline of the test specimen gage length at equally spaced locations. Due to the ITM test setup, it became necessary to turn off the heat guns, remove them from the high-speed digital camera view, and then prepare for the drop event, a time span that typically took about 15 seconds. Therefore, the test specimen was over-heated so that this preparation time interval could be incorporated into the test procedure. Hence, the higher steady-state temperatures were achieved, the heat guns were turned off, the test preparations were made while the test specimen was cooling down to the desired target temperature, and then the impact event was triggered. Performing the baseline temperature testing with the test specimen mounted in the tensile test fixture eliminated handling of a hot test specimen, avoided a full temperature heat-up of the entire tensile test fixture made of A36 carbon steel, and incorporated the cooling effects of the tensile test fixture.

In order to achieve acceptable test specimen temperature tolerances, a very prescriptive heat-up process was used. The settings for the heat guns, marked during baseline testing, were achieved by adjusting to a full power setting and then reducing the setting down to the desired power level. Using a digital timer, precise timing requirements, established during the baseline temperature testing, were followed for heat-up times, the time interval after heat guns were turned off for release of the drop weight, and for cooldown times between tests. A continuous timing sequence was used that began at the start of a test day and ended with the end of testing. Actual test specimens used for impact testing did not have any thermocouples attached to avoid deleterious affects. Temperatures of the test specimen or test specimen holder were measured (as was done during baseline temperature testing) using a contact thermocouple prior to each impact test to assure acceptable test specimen temperature ranges had been achieved. 
Table 1 indicates the worst-case temperature tolerances achieved during the numerous baseline temperature tests completed. For most of the tests, the weighted average temperature and maximum and minimum temperatures were much closer to the target test temperatures. The weighted average temperature covers the entire gage length whereas the $\mathrm{max} / \mathrm{min}$ temperature ranges are the highest or lowest temperature regardless of specific location.

Table 1. Temperature Tolerances for Impact Testing

\begin{tabular}{|c|c|c|}
\hline $\begin{array}{c}\text { Target Temp. } \\
\left({ }^{\circ} \mathrm{F}\right)\end{array}$ & $\begin{array}{c}\text { Weighted Avg. Temp. } \\
\text { Range }\left({ }^{\circ} \mathrm{F}\right)\end{array}$ & $\begin{array}{c}\text { Max/Min Temp. } \\
\text { Range }\left({ }^{\circ} \mathrm{F}\right)\end{array}$ \\
\hline 300 & $+15 /-10$ & $+25 /-25$ \\
\hline 600 & $+15 /-10$ & $+35 /-35$ \\
\hline
\end{tabular}

\section{IMPACT TENSILE TEST RESULTS}

This paper will discuss material impact tensile testing that occurred mainly during fiscal year 2006. Both 304L and 316L material test specimens at room, 300 , and $600^{\circ} \mathrm{F}$ temperatures were subjected to dynamic impact loads in order to achieve target strain rates of 5, 10, and 22 per second. Higher strain rates at the lower temperatures were achieved, when possible.

Figure 2 illustrates the typical test specimen geometries used for material impact testing. Test specimens made from $1 / 4-$ inch thick material were used for 5 and 10 per second strain rates and $1 / 2$-inch thick test specimens were used for higher strain rates. Square cross-section profiles were used for all impact test specimens. The $1 / 4$-inch and $1 / 2$-inch material were from different heats.

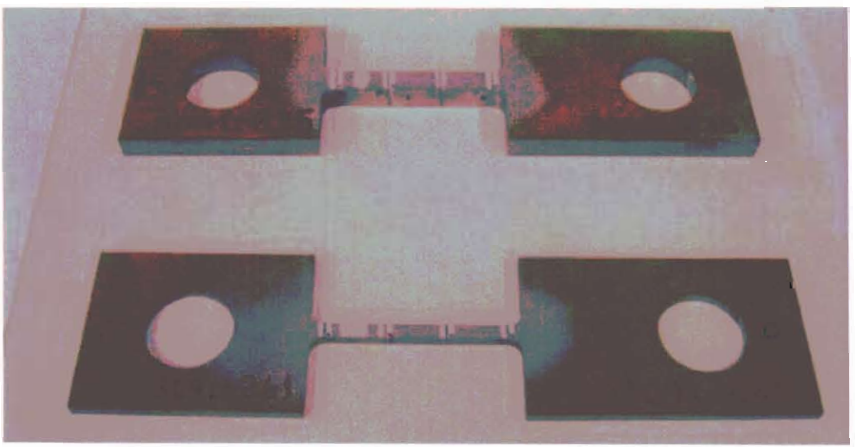

Figure 2. Test Specimens Used For Material Impact Testing

Quasi-static tensile test results provide the baseline for understanding how strain rate effects change a true stress-strain curve. Quasi-static tensile testing was performed following the requirements of ASTM A370-03a. Another paper for this conference (paper PVP2007-26096) contains additional information on the quasi-static testing performed to support this strain rate testing effort. Material impact testing, using the ITM, yielded the actual strain history response of the test specimen to a defined level of impact energy. Using the "total impact energy method" previously discussed, the amount of impact energy absorbed by the test specimen was compared to the amount of energy under the quasi-static true stress strain curve to determine the factors.
Room temperature material impact response information was obtained in the past with acceptable test specimen geometries. Incorporating that past factor information with the current test factor results allowed for the development of strain rate versus factor curves at room temperature that are well populated. The elevated temperature curves contain only test results from the FY06 testing and are less populated but still contain quantifiable indications of elevated true stress-strain curves at varying strain rates. The significance of these curves is that one is able to predict how much a strain rate curve will increase relative to the quasi-static stress-strain curve without having to perform specific strain rate testing. These factor curves are presented with the acknowledgement that the full range of strain rate information has not yet been achieved so the presented curves are indeed limited to the range of strain rates indicated. The assumption of a linear variation was deemed acceptable at present but may very well change with additional data at higher strain rates. Figures 3 through 5 illustrate the applicable factors for 304L material at room, 300, and $600^{\circ} \mathrm{F}$ temperatures respectively. Figures 6 through 8 illustrate the same information but for $316 \mathrm{~L}$ material.

Using the linear curve fit information from the factor curve relationships, the elevated true stress-strain curves can be generated, allowing for further insights to be more clearly recognized. Figures 9 through 11 illustrate the elevated true stress-strain curves for 304L stainless steel at 0 (quasi-static results), 5, 10, and 22 per second strain rates at room, 300, and $600^{\circ} \mathrm{F}$ temperatures respectively. Figures 12 through 14 illustrate the same information but for $316 \mathrm{~L}$ material.

Although the testing has not yet completed investigating the entire strain range of interest, certain insights can be observed by evaluating the data currently available. The elevated true stress-strain curves (Figures 9 through 14) clearly illustrate that strain rate effects do indeed increase the true stress-strain curves as the strain rate increases. Comparing $304 \mathrm{~L}$ versus $316 \mathrm{~L}$ curves, the increased capacity to absorb impact energy appears more significant in the $304 \mathrm{~L}$ than in the $316 \mathrm{~L}$ material. In fact, the data currently indicates that the 316L material may see a decreasing rate of impact energy absorption capacity as the strain rate increases whereas the 304L material appears to not have such a significant decreasing rate. Figures 15 and 16 illustrate how the enhanced true stressstrain curves vary at a strain rate of 22 per second with temperature. These two figures both indicate that at the same strain rate, increasing temperature decreases the strain rate gain in strength. More subtle effects can be characterized by looking at the actual factors shown in Table 2. The $316 \mathrm{~L}$ material has a greater capacity to absorb impact energy at lower strain rates but the $304 \mathrm{~L}$ material has a greater capacity to absorb impact energy at higher strain rates. Finally, as indicated previously with respect to Figures 15 and 16 , the strain rate factor actually decreases with increasing temperature. 
304L Factors at Room Temperature

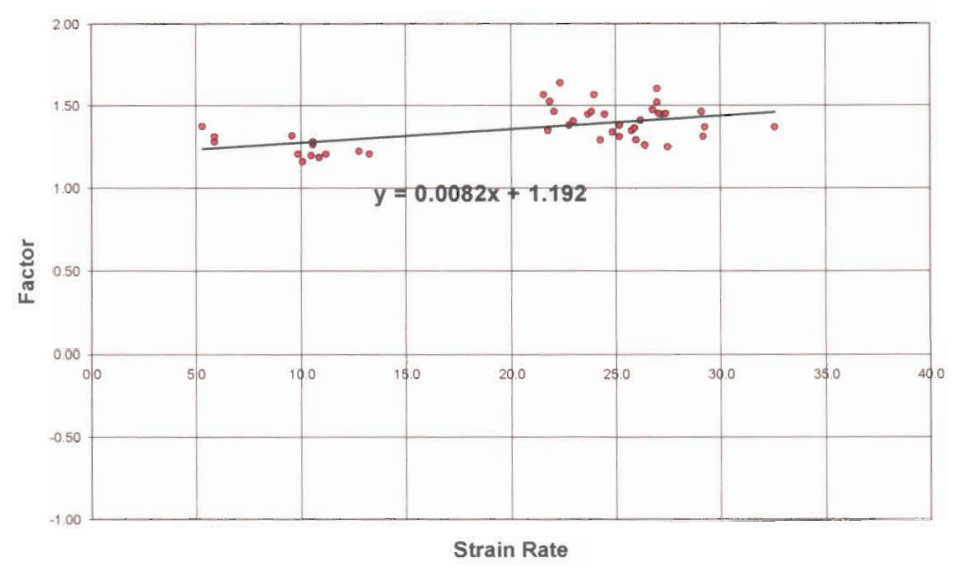

Figure 3. Factor Versus Strain Rate at Room Temperature for 304L

304L Factors at $300 \mathrm{~F}$

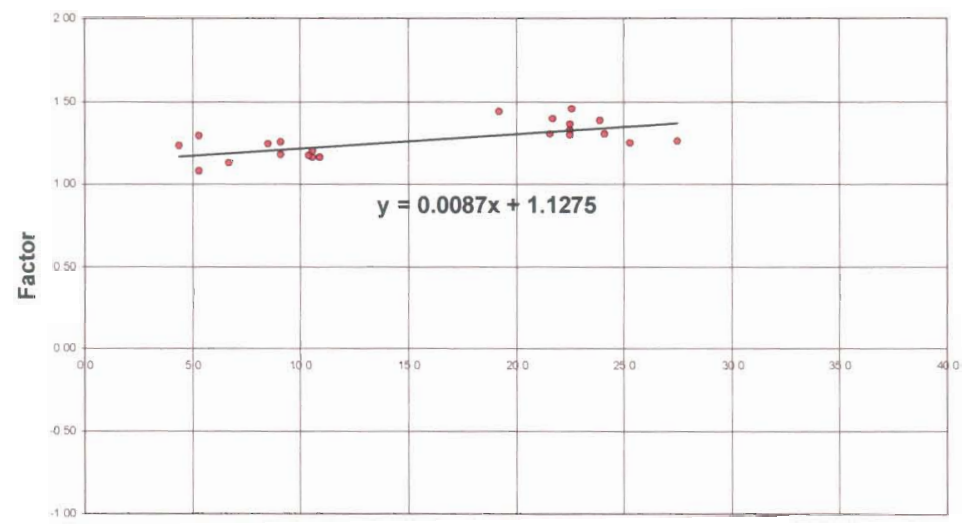

Strain Rate

Figure 4. Factor Versus Strain Rate at 300F Temperature for 304L

304L Factors at 600F

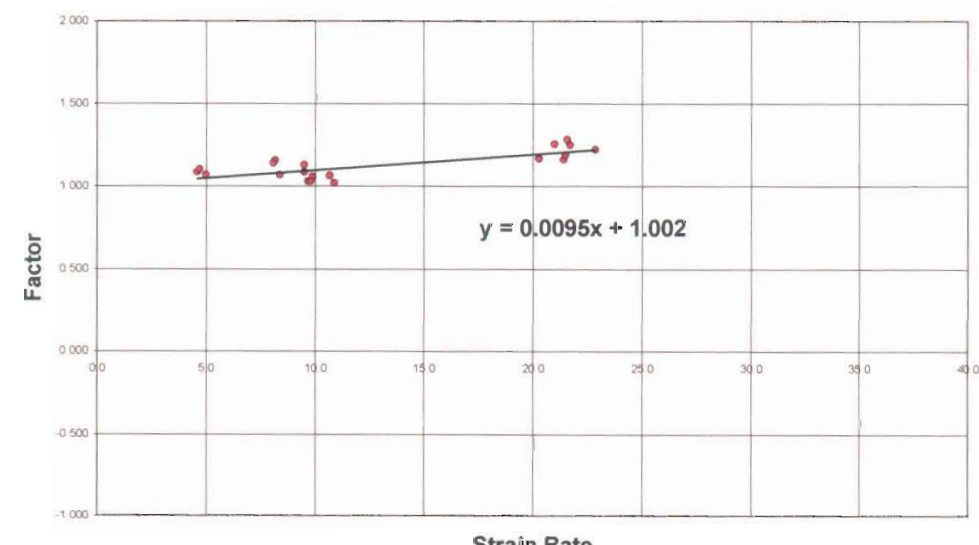

Strain Rate

Figure 5. Factor Versus Strain Rate at 600F Temperature for $304 \mathrm{~L}$ 
316L Factors at Room Temperature

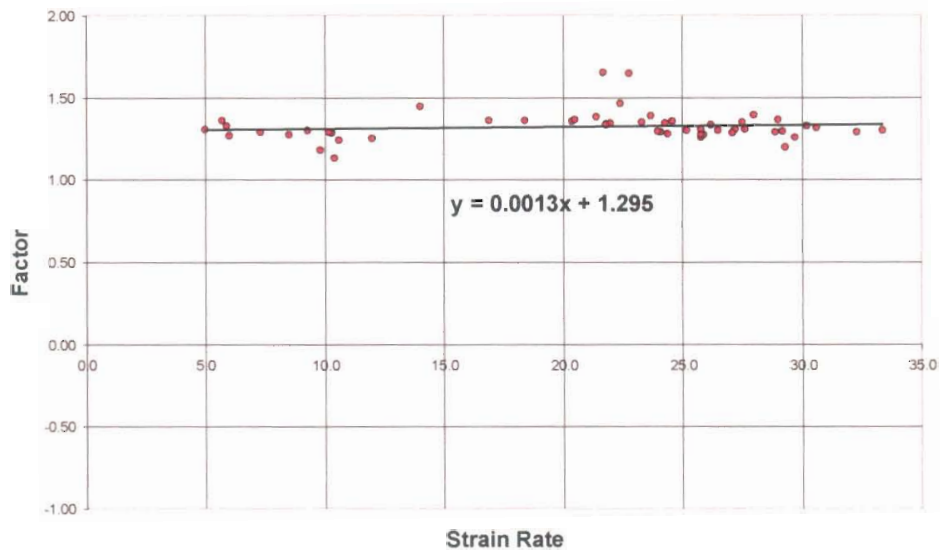

Figure 6. Factor Versus Strain Rate at Room Temperature for 316L

$316 \mathrm{~L}$ Factors at $300 \mathrm{~F}$

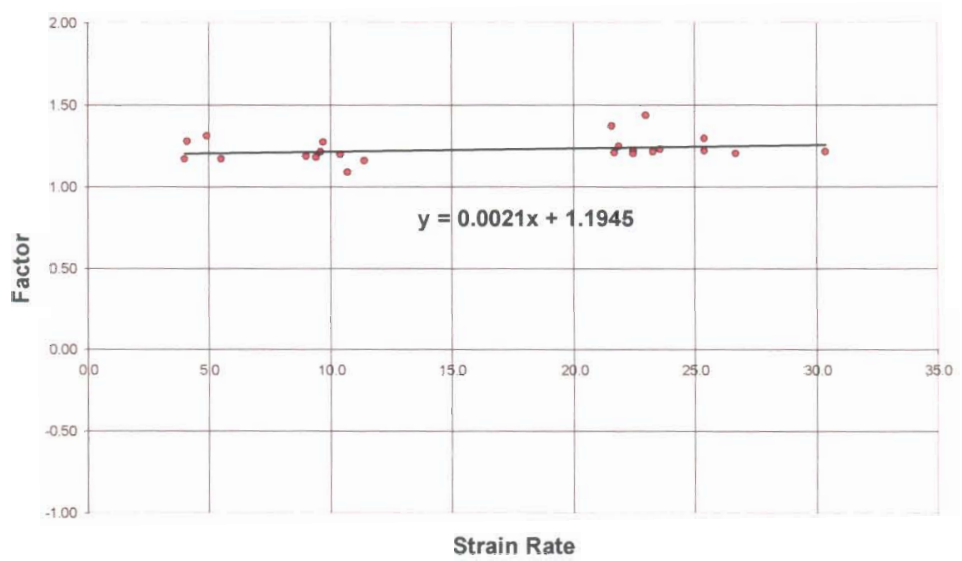

Figure 7. Factor Versus Strain Rate at $300 \mathrm{~F}$ Temperature for $316 \mathrm{~L}$

$316 \mathrm{~L}$ Factors at $600 \mathrm{~F}$

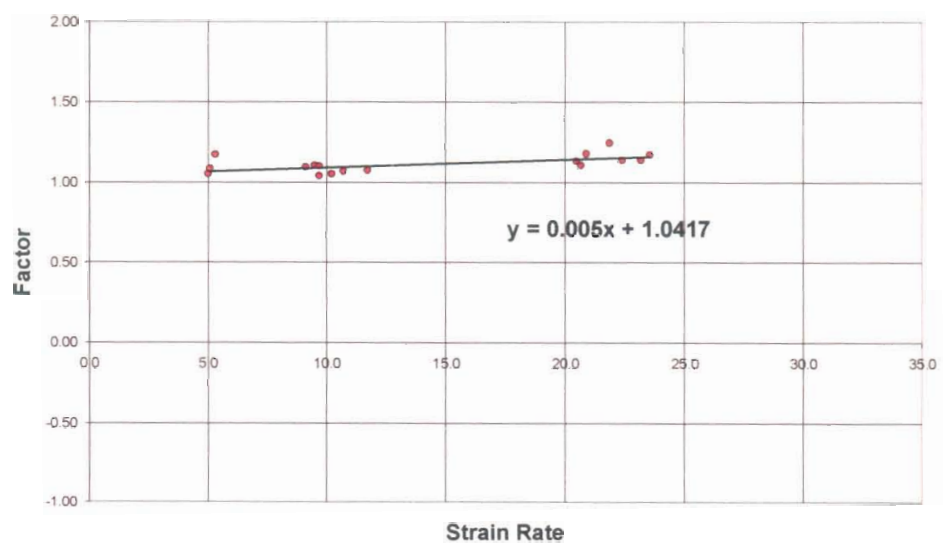

Figure 8. Factor Versus Strain Rate at $600 \mathrm{~F}$ Temperature for $316 \mathrm{~L}$ 
304L True Stress-Strain Curve at Room Temperature With Varying Strain Rates

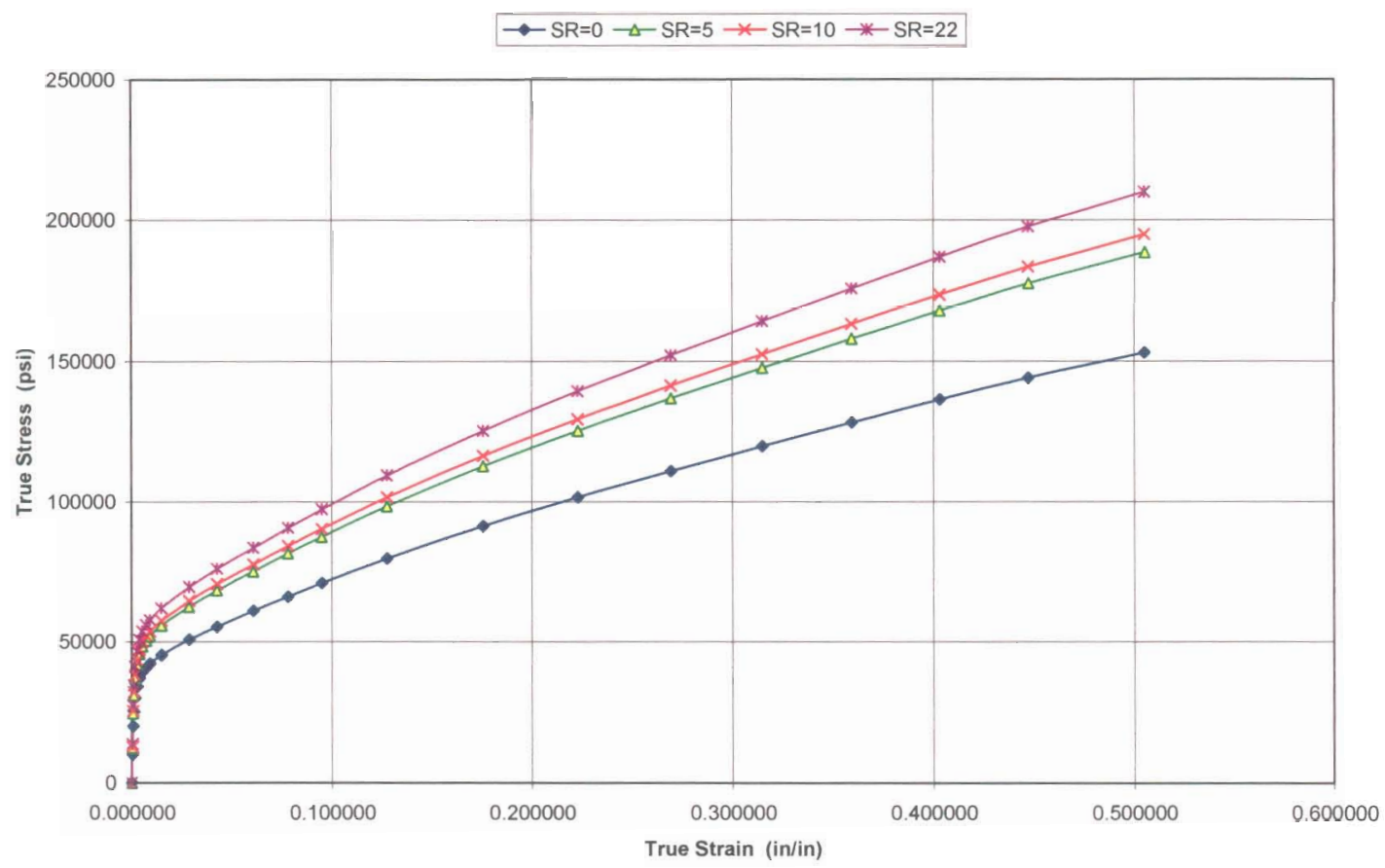

Figure 9. 304L True Stress-Strain Curve at Room Temperature with Varying Strain Rates 304L True Stress-Strain Curve at 300F With Varying Strain Rates

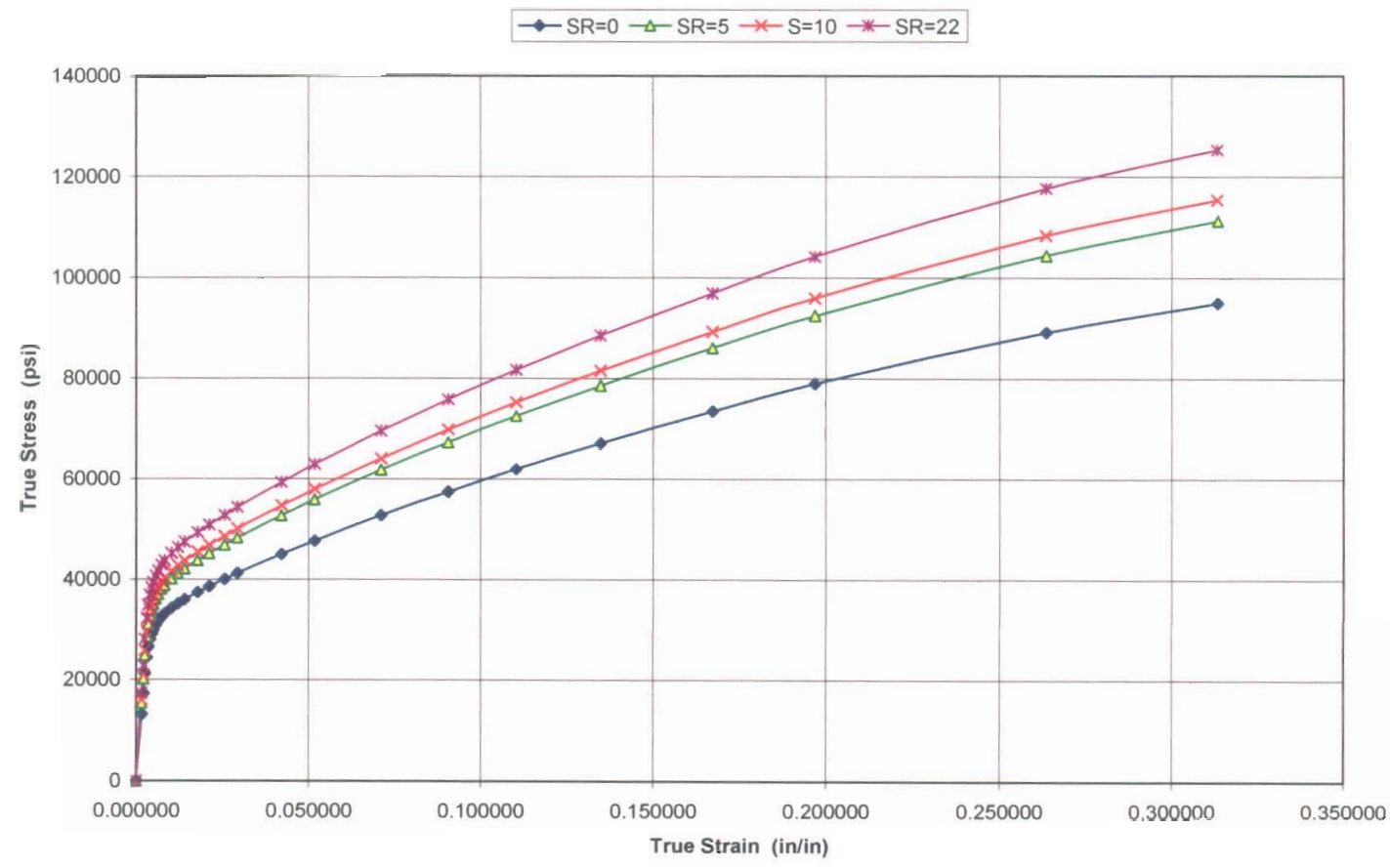

Figure 10. 304L True Stress-Strain Curve at $300^{\circ} \mathrm{F}$ Temperature with Varying Strain Rates 
304L True Stress-Strain Curves at 600F With Varying Strain Rates

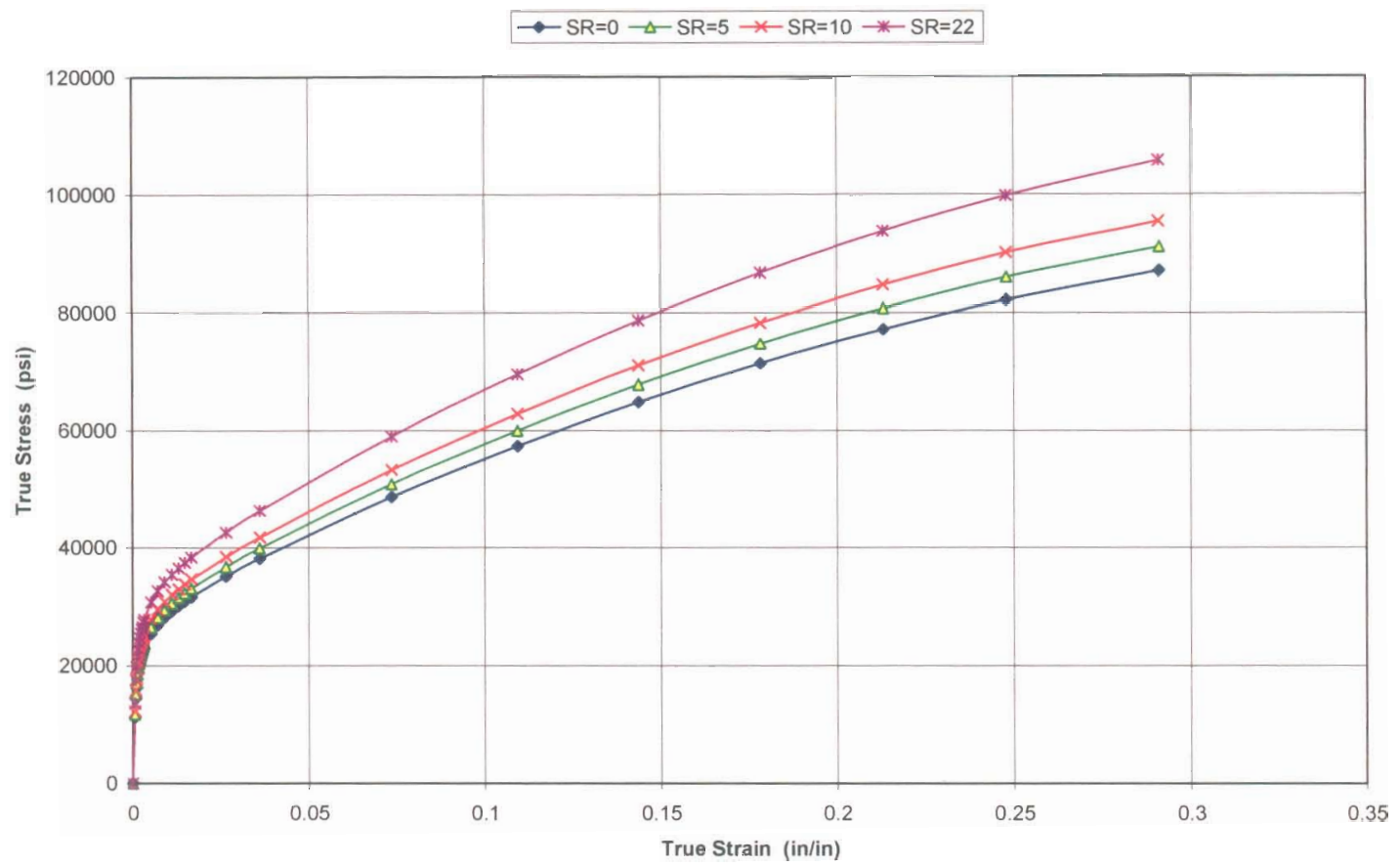

Figure 11. 304L True Stress-Strain Curve at $600^{\circ} \mathrm{F}$ Temperature with Varying Strain Rates 316L True Stress-Strain Curve at Room Temperature With Varying Strain Rates

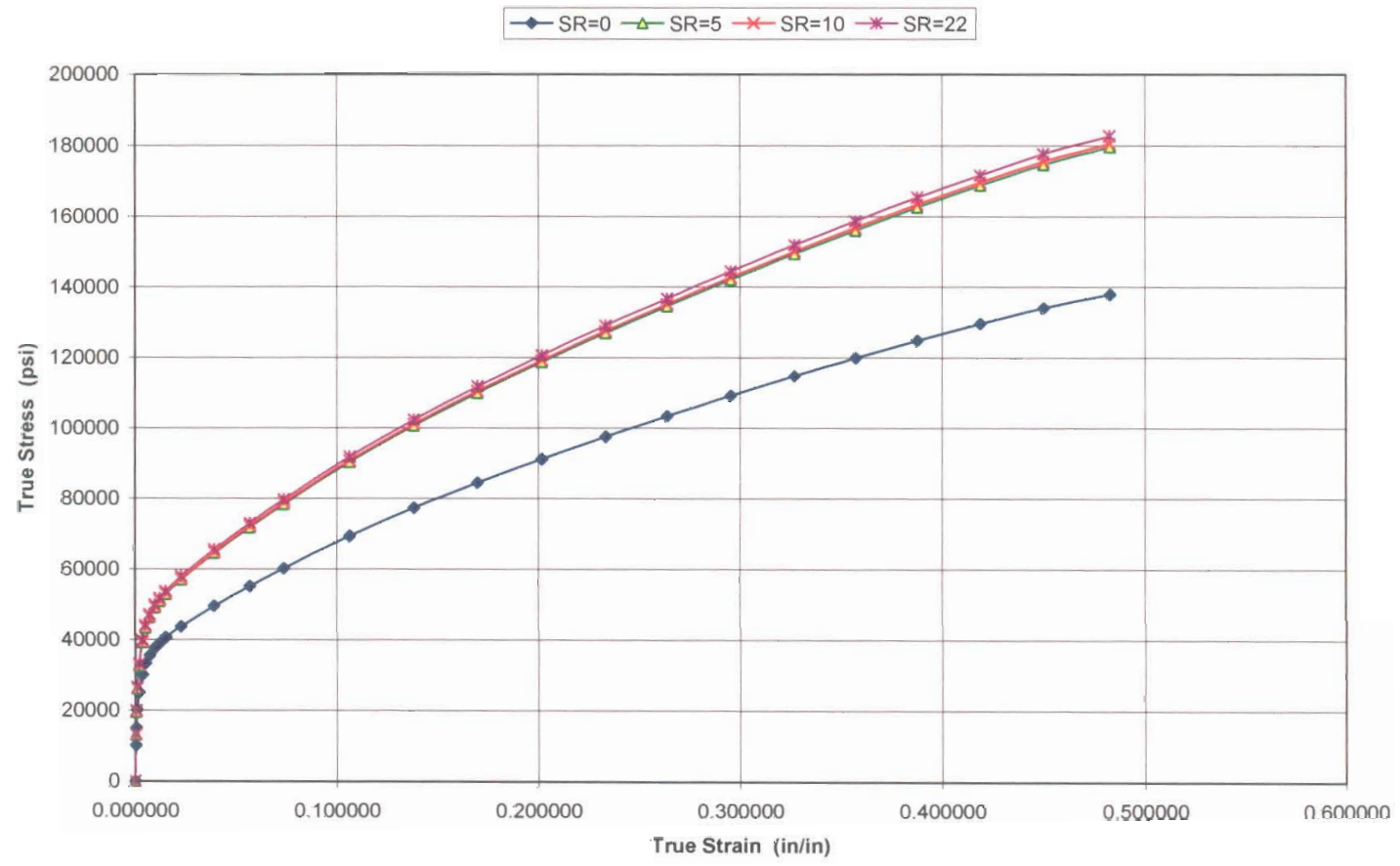

Figure 12. 316L True Stress-Strain Curve at Room Temperature with Varying Strain Rates 
316L True Stress-Strain Curve at 300F With Varying Strain Rates

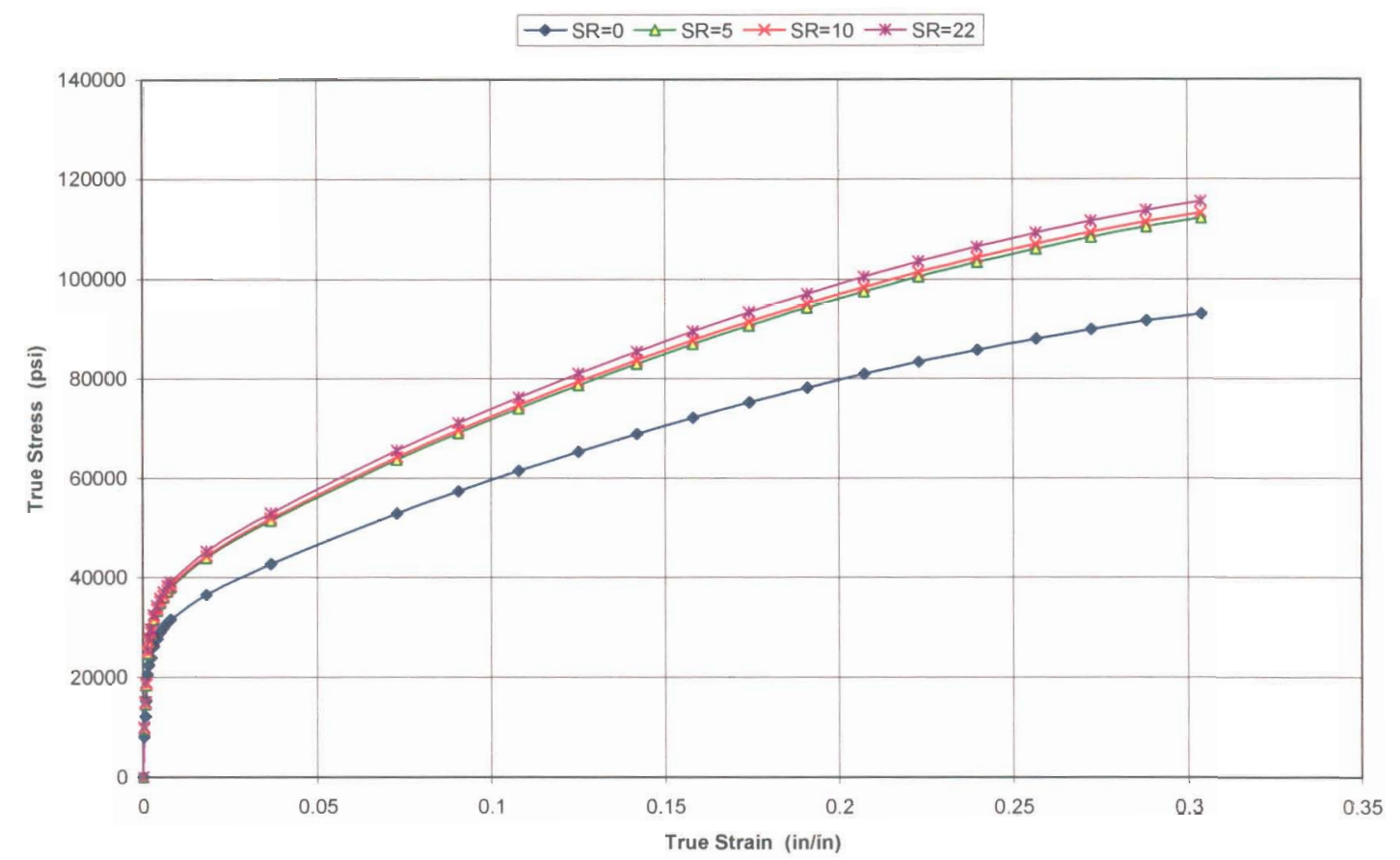

Figure 13. 316L True Stress-Strain Curve at $300^{\circ} \mathrm{F}$ Temperature with Varying Strain Rates 316L True Stress-Strain Curve at 600F With Varying Strain Rates

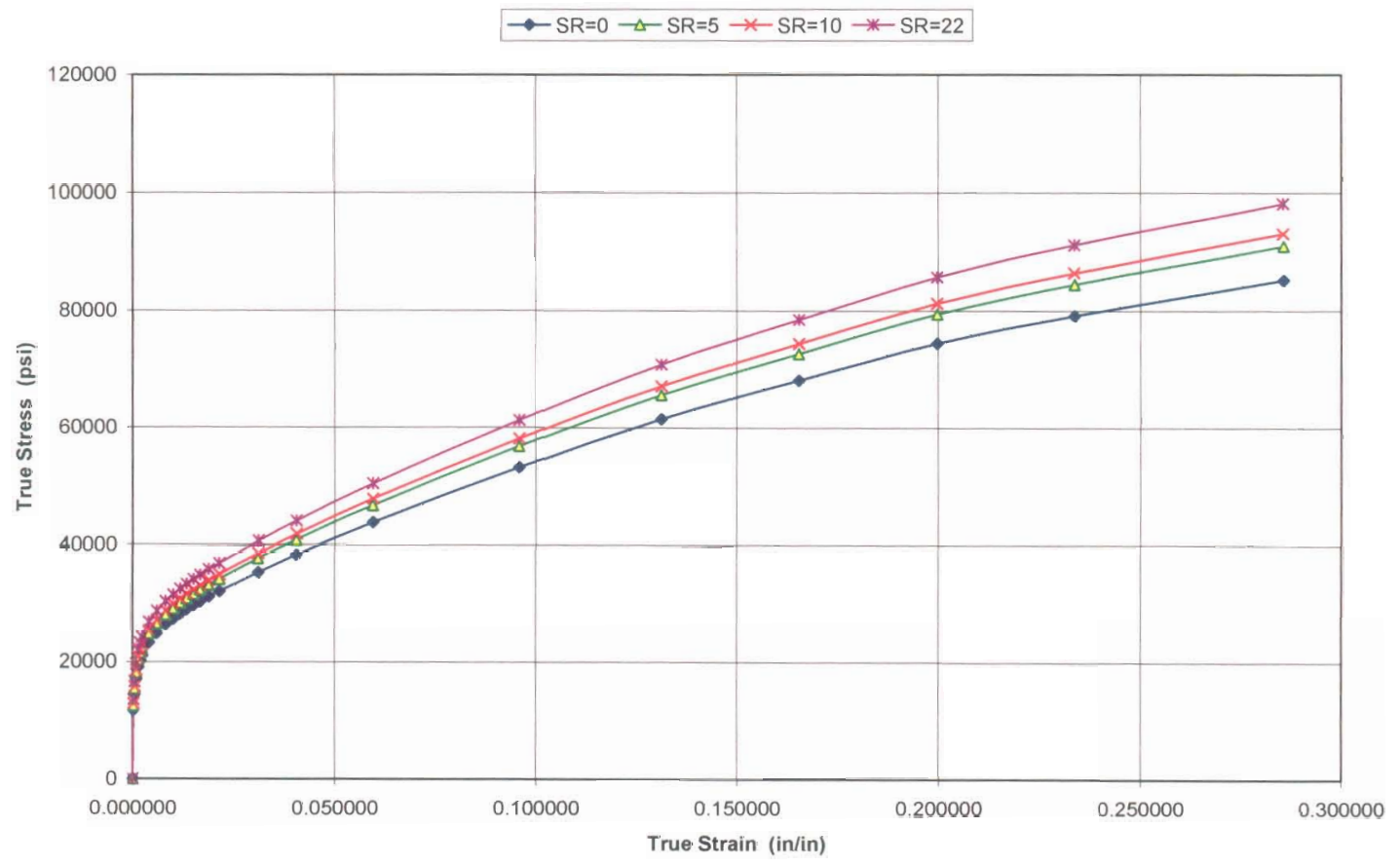

Figure 14. 316L True Stress-Strain Curve at $600^{\circ} \mathrm{F}$ Temperature with Varying Strain Rates 
304L Stress-Strain At 22 Per Second Strain Rate With Varying Temperatures

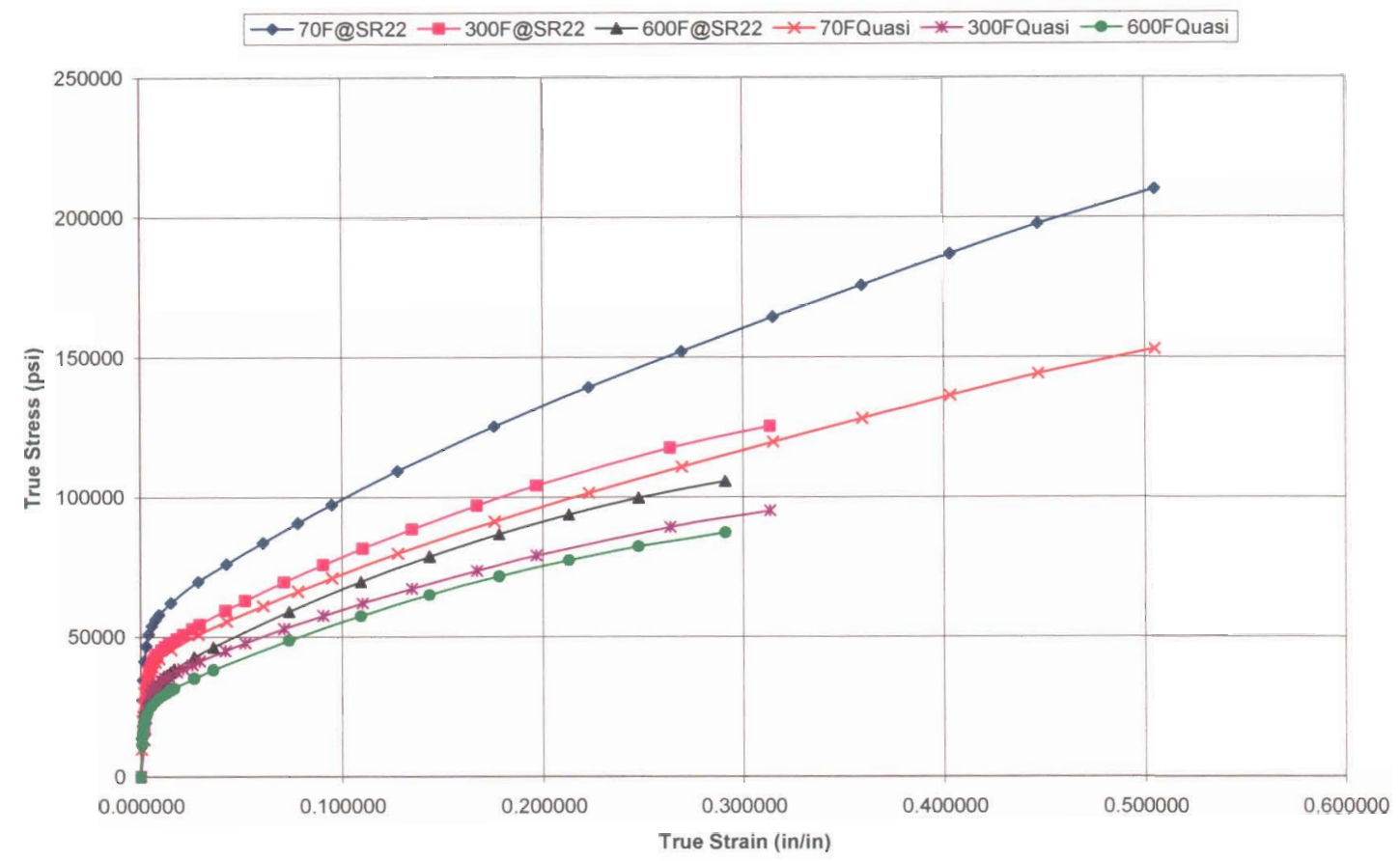

Figure 15. Variation of $304 \mathrm{~L}$ True Stress-Strain Curve With Temperature at 22 Per Second Strain Rate

316L Stress-Strain At 22 Per Second Strain Rate With Varying Temperatures

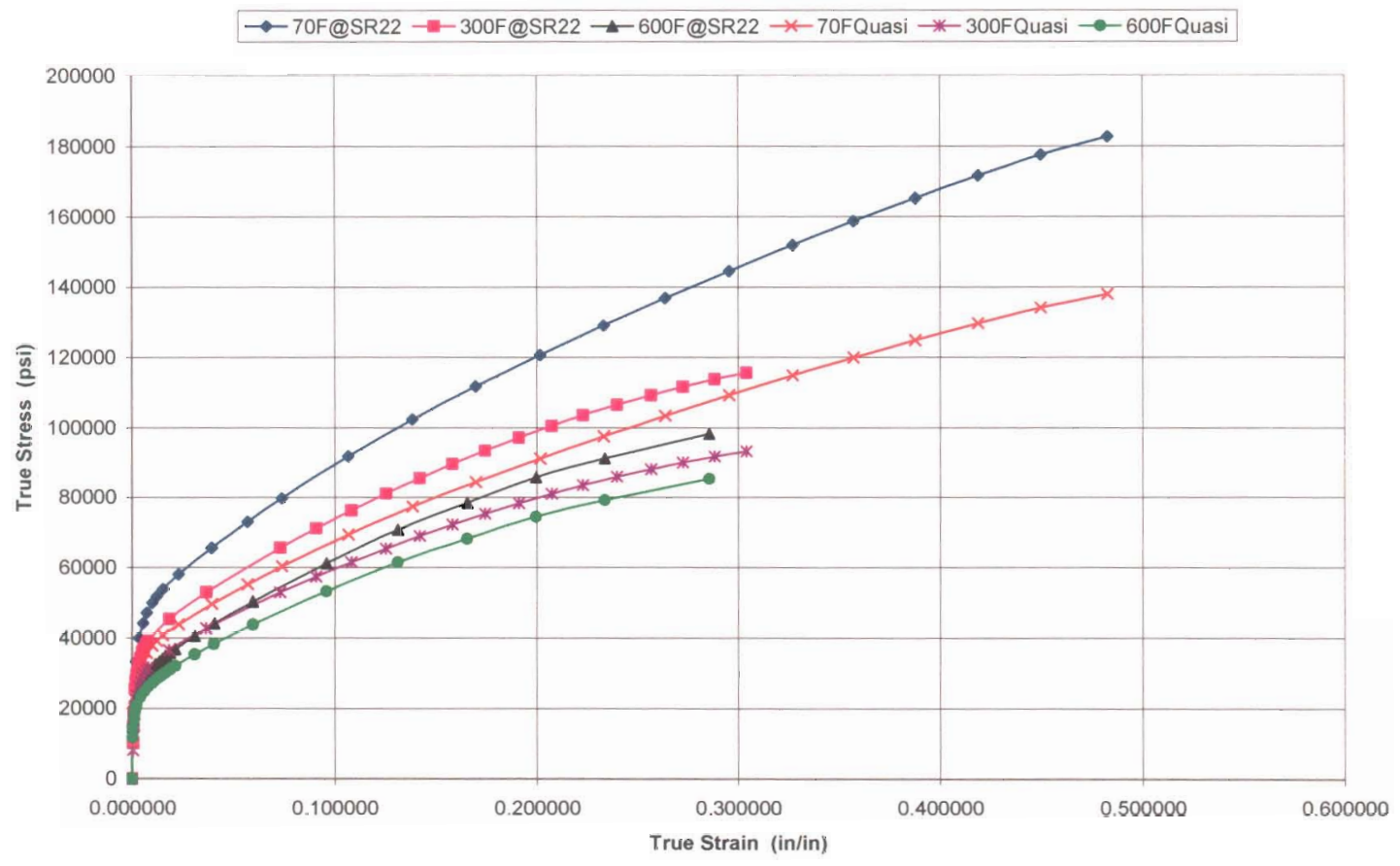

Figure 16. Variation of 316L True Stress-Strain Curve With Temperature at 22 Per Second Strain Rate 
Table 2. Factors For Specified Strain rates

\begin{tabular}{|c|c|c|c|}
\hline $\begin{array}{c}\text { Strain rate } \\
\text { per sec }\end{array}$ & $\begin{array}{c}\text { Room } \\
\text { Temperature }\end{array}$ & $\begin{array}{c}300 \\
{ }^{\circ} \mathrm{F}\end{array}$ & $\begin{array}{c}600 \\
{ }^{\circ} \mathrm{F}\end{array}$ \\
\hline \multicolumn{4}{|c|}{$304 \mathrm{~L}$ Stainless Steel } \\
\hline 5 & 1.233 & 1.171 & 1.046 \\
\hline 10 & 1.274 & 1.215 & 1.096 \\
\hline 22 & 1.372 & 1.319 & 1.214 \\
\hline \multicolumn{5}{|c|}{$316 \mathrm{~L}$ Stainless Steel } \\
\hline 5 & 1.302 & 1.205 & 1.067 \\
\hline 10 & 1.308 & 1.216 & 1.092 \\
\hline 22 & 1.324 & 1.241 & 1.152 \\
\hline
\end{tabular}

A number of analyses were performed of the impact tests using the plastic analysis software ABAQUS/Explicit [4] with material properties modeled as non-factored and factored true stress-strain input. Table 3 provides percentage comparisons of both analysis prediction methods (using non-factored and factored data) to the actual post-impact deformed gage lengths (considering the entire gage length) and the resulting gage length deformations (considering only the resulting gage length deformations). The Table 3 results clearly indicate that the strain rate adjusted (factored) input results in more accurate predictions than when just the quasi-static (nonfactored) true stress-strain curves are used.

Table 3. Comparison of Using Factored Versus Non-Factored True Stress-Strain Input

\begin{tabular}{|c|c|c|}
\hline \multicolumn{3}{|c|}{ Analysis Accuracy } \\
\hline Parameter Evaluated & Non-Factored & Factored \\
\hline $\begin{array}{c}\text { Deformed } \\
\text { Gage Lengths }\end{array}$ & 1 to $6 \%$ & 0 to $3 \%$ \\
\hline $\begin{array}{c}\text { Resulting Axial } \\
\text { Deformations }\end{array}$ & 10 to $55 \%$ & 0 to $19 \%$ \\
\hline
\end{tabular}

\section{CONCLUSIONS}

The material impact testing reported herein has provided data to support the development of factors applicable to the quasi-static true stress-strain curve for both $304 \mathrm{~L}$ and $316 \mathrm{~L}$ stainless steels that account for strain rate strengthening up to a strain rate of approximately $33 /$ second. Impact tensile testing is continuing at the INL to achieve higher strain rates for the associated factor curves. With the higher strain rate data, the linear curve fit used herein may prove to be inadequate. Final conclusions regarding why the room temperature and $300^{\circ} \mathrm{F}$ linear curve fits do not trend toward unity as the strain rate goes to zero will not be made at this time. However, for the strain rate range presented herein, the linear curve fit does provide insights into the acceptability of the data that reflects different thicknesses and different heats.

The application of strain rate dependent true stress-strain curves generated from impact tensile testing to analytical models of multiple dynamic tensile tests discussed in this paper resulted in analytical predictions that matched very well with the actual deformations and strains in the tensile test specimens. The elevated strain rate curves developed can be used in analytical simulations to more accurately predict the deformation and resulting material straining in spent nuclear fuel containers, canisters, and casks loaded by accidental drop events.

The goal of the NSNFP's test program is to develop curve factors for strain rates of up to 200 /second for application to stainless steel components subjected to impact events. Data produced in this test program may also be used in the development of strain-based acceptance criteria for application to SNF containers, canisters, and casks experiencing accidental impact events.

\section{REFERENCES}

[1] Snow, S. D.; Morton, D. K.; Rahl, T. E.; Blandford, R. K.; Hill, T. J.; 2004, "Preliminary Elevated Strain Rate Material Testing to Support Accidental Drop Analyses of Radioactive Material Containers, " American Society of Mechanical Engineers Pressure Vessels \& Piping Conference, Transportation, Storage, and Disposal of Radioactive Materials, PVP-Vol. 483, pp. 197-201.

[2] Blandford, R. K.; Morton, D. K.; Rahl, T. E.; Snow, S. D.; 2005, "Impact Testing of Stainless Steel Materials," American Society of Mechanical Engineers Pressure Vessels and Piping Conference, PVP2005-71133.

[3] Snow, S. D., Morton, D. K.; Rahl, T. E.; Blandford, R. K.; Hill, T. J.; 2006, "Preliminary Results of Stainless Steel Impact Bending Tests," American Society of Mechanical Engineers Pressure Vessels and Piping Conference, PVP2006ICPVT-11-93161.

[4] ABAQUS/Explicit Version 6.6-3, 2006, ABAQUS, Inc.

\section{NOTICE}

This paper was prepared as an account of work sponsored by an agency of the U. S. Government. Neither the U. S. Government nor any agency thereof, or any of their employees, makes any warranty, expressed or implied, or assumes any legal liability or responsibility for any third party's use, or the results of such use, of any information, apparatus, product or process disclosed in this report, or represents that its use by such third party would not infringe privately owned rights. The views expressed in this paper are not necessarily those of the U.S. DOE.

This material is declared a work of the U.S. Government and is not subject to copyright protection in the United States. Approved for public release; distribution is unlimited. 